\title{
ЛЕЧЕНИЕ И ПРОФИЛАКТИКА
}

УДК 619:616.995.1-085

DOI:

Поступила в редакцию 01.12.2016

Принята в печать 10.03.2017

\section{Для цитирования:}

Варламова А. И., Архипов И. А. Спектр антигельминтной активности супрамолекулярного комплекса фенбендазола с арабиногалактаном // Российский паразитологический журнал. - 2017. - T.39.- Bыn.1 . - C.

\section{For citation:}

Varlamova A. I., Arkhipov I. A. Spectrum of anthelmintic activity of supramolecular complex of fenbendazole with arabinogalactan. Russian Journal of Parasitology, 2017, Vol.39, Iss. 1, pp.

\section{СПЕКТР АНТИГЕЛЬМИНТНОЙ АКТИВНОСТИ СУПРАМОЛЕКУЛЯРНОГО КОМПЛЕКСА ФЕНБЕНДАЗОЛА С АРАБИНОГАЛАКТАНОМ}

\section{А. И. Варламова, И. А. Архипов}

Всероссийский научно-исследовательский институт фундаментальной и прикладной паразитологии животных и растений им. К. И. Скрябина, 117218 , Москва, ул. Б. Черемушкинская, д. 28, e-mail: arkhipov@ vniigis.ru

\footnotetext{
Реферат

Цель исследования - изучение биологической активности супрамолекулярного комплекса фенбендазола с арабиногалактаном при гельминтозах овец с учетом спектра действия.

Материалы и методы. Антигельминтную активность супрамолекулярного комплекса фенбендазола с арабиногалактаном (СМКФ) изучали в овцеводческих хозяйствах Московской и Самарской областей, неблагополучных по гельминтозам. Опыты проводили в 2014-2015 гг. в период максимальной инвазированности животных. В опытах использовали 386 голов молодняка овец, в том числе спонтанно инвазированных диктиокаулами 50 гол., нематодирусами 48 гол., другими видами желудочно-кишечных стронгилят 52 гол., фасциолами 47 гол., дикроцелиями 49 гол., стронгилоидами 42 гол., трихоцефалами 44 гол., мониезиями 54 гол. При каждом гельминтозе животных по принципу аналогов разделяли на 6 равноценных групп по 7-10 овец в каждой. Животным первой, второй и третьей групп вводили СМКФ в форме 10\%-ного порошка однократно перорально в дозе соответственно 1,0; 2,0 и 3,0 мг/кг по ДВ. Овцы четвертой и пятой групп получали базовый препарат - фенбендазол в дозах соответственно 1,0 и 7,5 мг/кг за исключением, когда СМКФ при фасциолезе и дикроцелиозе назначали в дозах 15,$0 ; 7,5$ и 5,0 мг/кг, а фенбендазол - в дозах 6,0 и 15,0 мг/кг. Животные контрольной группы препарат не получали. Эффективность СМКФ учитывали по результатам ларвоовоскопических исследований фекалий методом
} 
Бермана при диктиокаулезе, методом флотации при других гельминтозах до и через 15-18 сут после дегельминтизации. Учет активности препаратов проводили по типу «контрольный тест» с расчетом среднего числа обнаруженных личинок и/или яиц гельминтов.

Результаты и обсуждение. В опытах на 386 овцах, спонтанно инвазированных различными видами гельминтов, изучен спектр антигельминтного действия и установлена терапевтическая доза СМКФ с арабиногалактаном, полученного по механохимической технологии. СМКФ показал максимальную эффективность (96-100 \%) при основных гельминтозах в дозе 3,0 мг/кг по ДВ, а при дикроцелиозе и фасциолезе - в дозе 15,0 мг/кг по ДВ. Эффективность СМКФ оказалась в 2-3 раза выше активности субстанции фенбендазола.

Ключевые слова: овцы, супрамолекулярный комплекс, фенбендазол, арабиногалактан, эффективность, гельминтозы.

\section{Введение}

Фенбендазол (панакур) - препарат из группы бензимидазолов, обладает широким спектром действия [6,7]. Он эффективен при нематодозах животных в дозе 7,5-10 мг/кг, против протостронгилид - в дозе 15 мг/кг, при фасциолезе и дикроцелиозе - в дозе 100 мг/кг [1]. Препарат менее активен при трихоцефалезе и стронгилоидозе [6]. Кроме того, известно, что фенбендазол согласно биофармацевтической классификации FDA относится к IV классу препаратов с низкой проницаемостью и растворимостью, т. е. имеет плохую биодоступность [11]. Следовательно, данный антигельминтик нуждается в технологиях повышения его водорастворимости.

Для повышения растворимости лекарств используют различные физикохимические методы: уменьшение размеров частиц, модификация кристаллической структуры, получение твердых дисперсий лекарственных веществ с наполнителями и т. д. [8, 9]. Управление солюбилизационными характеристиками лекарственных веществ является одним из основных направлений в разработках современных систем доставки лекарств Drug Delivery System $[5,10]$.

В связи с этим большой интерес представлял поиск путей повышения эффективности фенбендазола и расширения спектра его действия путем использования механохимических подходов, методов комплексообразования типа «гость - хозяин» и приемов нанотехнологии для улучшения растворимости, проницаемости и, как следствие, биодоступности фенбендазола.

В предыдущие годы нами испытан СМКФ при отдельных нематодозах овец и крупного рогатого скота [2, 3] и получен Патент на этот препарат [4].

Цель нашей работы - оценка спектра действия и антигельминтных свойств супрамолекулярного комплекса фенбендазола (СМКФ), полученного по технологии механохимической модификации субстанции с использованием адресной доставки Drug Delivery System c полимером растительного происхождения - арабиногалактаном.

\section{Материалы и методы}

Антигельминтную активность СМКФ с арабиногалактаном изучали в овцеводческих хозяйствах Московской и Самарской областей, неблагополучных по гельминтозам.

Опыты проводили в 2014-2015 гг. в период максимальной инвазированности животных. В опытах использовали 386 голов молодняка овец 
разных пород массой тела от 15 до 35 кг, в том числе спонтанно инвазированных диктиокаулами 50 гол., нематодирусами 48 гол., другими видами желудочнокишечных стронгилят 52 гол., фасциолами 47 гол., дикроцелиями 49 гол., стронгилоидами 42 гол., трихоцефалами 44 гол., мониезиями 54 гол. При каждом гельминтозе животных по принципу аналогов разделяли на 6 равноценных групп по 7-10 овец в каждой. Животным первой, второй и третьей групп вводили СМКФ в форме $10 \%$-ного порошка однократно перорально в дозе соответственно 1,$0 ; 2,0$ и 3,0 мг/кг по ДВ. Овцы четвертой и пятой групп получали базовый препарат - фенбендазол (субстанцию, на основе которой приготовлен СМКФ) в дозах соответственно 1,0 и 7,5 мг/кг за исключением, когда СМКФ при фасциолезе и дикроцелиозе назначали в дозах 15,0; 7,5 и 5,0 мг/кг, а фенбендазол - в дозах 5,0 и 15,0 мг/кг. Животные контрольной группы препарат не получали.

Эффективность СМКФ учитывали по результатам ларвоовоскопических исследований фекалий методом Бермана при диктиокаулезе, методом флотации при других гельминтозах до и через 15-18 сут после дегельминтизации. Учет активности препаратов проводили по типу «контрольный тест» с расчетом среднего числа обнаруженных личинок и/или яиц гельминтов [1]. Полученные результаты обработали статистически с использованием компьютерной программы Microsoft Excel 2003 - 2007.

\section{Результаты и обсуждение}

Полученные результаты приведены в таблице и свидетельствуют о различной степени эффективности СМКФ в разных дозах против различных видов гельминтов.

Нематодироз. СМКФ в дозах 3,0; 2,0 и 1,0 мг/кг по ДВ проявил соответственно 100; 97,57 и 94,94\%-ную эффективность по результатам исследований проб фекалий методом флотации. Животные полностью освободились от нематодирусов после применения комплекса в дозе 3,0 мг/кг (ЭЭ $100 \%) .6$ из 8 овец также оказались свободными от нематод после введения препарата в дозе 2,0 мг/кг по ДВ, а число яиц нематодирусов в фекалиях снизилось на 97,57 \%. После дачи комплекса в дозе 1,0 мг/кг 5 из 8 животных оказались свободными от инвазии. Эффективность составила 94,94 \%.

Эффективность базового препарата - субстанции фенбендазола составила в дозе 5,0 мг/кг 95,28 и в дозе 1,0 мг/кг 8,62 \%.

Инвазированность овец контрольной группы в период опыта существенно не изменилась $(\mathrm{P}>0,05)$.

На основании полученных результатов терапевтической дозой СМКФ при нематодирозе рекомендуем считать дозу 3,0 мг/кг по ДВ.

Другие желудочно-кишечные стронгилятозы. СМКФ в дозах 3,0; 2,0 и 1,0 мг/кг по ДВ проявил соответственно 100; 97,66 и 94,83\%-ную эффективность (табл.). Субстанция фенбендазола в дозах 5,0 и 1,0 мг/кг показала соответственно 95,26 и 9,12\%-ную активность. Число яиц стронгилят в 1 г фекалий в начале и конце опыта составило соответственно $158,2 \pm 5,1$ и 162,3 $\pm 6,4$ экз. (P > 0,05). 


\section{Спектр активности СМКФ при гельминтозах овец}

\begin{tabular}{|c|c|c|c|c|c|c|c|}
\hline \multirow[t]{2}{*}{ Препарат } & \multirow{2}{*}{$\begin{array}{l}\text { Доза, } \\
\text { мг/кг, по } \\
\text { ДВ }\end{array}$} & \multirow[t]{2}{*}{$\begin{array}{l}\text { Число } \\
\text { овец }\end{array}$} & \multirow[t]{2}{*}{$\begin{array}{l}\text { Освободилось от } \\
\text { инвазии, гол. }\end{array}$} & \multicolumn{2}{|c|}{$\begin{array}{lll}\text { Среднее } & \text { число } & \text { яиц/личинок } \\
\text { гельминтов в } 1 \text { г фекалий, экз. }\end{array}$} & \multirow{2}{*}{$\begin{array}{l}\text { Снижение } \\
\text { яиц/личинок } \\
\text { гельминтов } \\
\text { фекалиях, \% }\end{array}$} & \multirow{2}{*}{$\begin{array}{r}\text { числа } \\
\text { в }\end{array}$} \\
\hline & & & & до опыта & после лечения & & \\
\hline 1 & 2 & 3 & 4 & 5 & 6 & 7 & \\
\hline \multicolumn{8}{|l|}{ Нематодироз } \\
\hline СМКФ & 3,0 & 8 & 8 & $140,2 \pm 5,0$ & 0 & 100 & \\
\hline СМКФ & 2,0 & 8 & 6 & $138,7 \pm 4,8$ & 3,5 & 97,57 & \\
\hline СМКФ & 1,0 & 8 & 5 & $139,5 \pm 5,1$ & $7,3 \pm 1,7$ & 94,94 & \\
\hline Фенбендазол & 1,0 & 8 & 0 & $141,2 \pm 4,9$ & $131,6 \pm 4,3$ & 8,62 & \\
\hline Фенбендазол & 5,0 & 8 & 5 & $140,6 \pm 4,8$ & $6,8 \pm 1,8$ & 95,28 & \\
\hline Контроль & - & 8 & 0 & $139,6 \pm 4,7$ & $144,0 \pm 5,7$ & - & \\
\hline \multicolumn{8}{|c|}{ Другие желудочно-кишечные стронгилятозы } \\
\hline СМКФ & 3,0 & 8 & 8 & $157,4 \pm 5,3$ & 0 & 100 & \\
\hline СМКФ & 2,0 & 9 & 6 & $156,6 \pm 5,4$ & $3,8 \pm 1,1$ & 97,66 & \\
\hline СМКФ & 1,0 & 9 & 5 & $158,2 \pm 5,1$ & $8,4 \pm 1,8$ & 94,83 & \\
\hline Фенбендазол & 1,0 & 8 & 0 & $158,4 \pm 4,9$ & $147,5 \pm 5,2$ & 9,12 & \\
\hline Фенбендазол & 5,0 & 9 & 6 & $156,9 \pm 5,0$ & $7,7 \pm 1,5$ & 95,26 & \\
\hline Контроль & - & 9 & 0 & $158,2 \pm 5,1$ & $162,3 \pm 6,4$ & - & \\
\hline \multicolumn{8}{|l|}{ Диктиокаулез } \\
\hline СМКФ & 3,0 & 8 & 8 & $117,4 \pm 6,7$ & 0 & 100 & \\
\hline СМКФ & 2,0 & 9 & 8 & $116,0 \pm 6,5$ & 4,0 & 96,73 & \\
\hline СМКФ & 1,0 & 9 & 5 & $118,5 \pm 7,0$ & $17,6 \pm 2,1$ & 85,61 & \\
\hline Фенбендазол & 1,0 & 8 & 0 & $119,3 \pm 6,9$ & $105,4 \pm 6,4$ & 13,82 & \\
\hline Фенбендазол & 5,0 & 8 & 6 & $120,4 \pm 6,8$ & 4,5 & 96,32 & \\
\hline Контроль & - & 8 & 0 & $117,2 \pm 6,7$ & $122,3 \pm 6,8$ & - & \\
\hline
\end{tabular}




\begin{tabular}{|c|c|c|c|c|c|c|}
\hline 1 & 2 & 3 & 4 & 5 & 6 & 7 \\
\hline \multicolumn{7}{|c|}{ Стронгилоидоз } \\
\hline СМКФ & 3,0 & 7 & 7 & $110,2 \pm 6,4$ & 0 & 100 \\
\hline СМКФ & 2,0 & 7 & 4 & $109,6 \pm 5,8$ & $32,0 \pm 2,8$ & \begin{tabular}{|l|}
71,98 \\
\end{tabular} \\
\hline СМКФ & 1,0 & 7 & 1 & $108,2 \pm 5,7$ & $75,4 \pm 5,2$ & 33,98 \\
\hline Фенбендазол & 1,0 & 7 & 0 & $111,0 \pm 5,9$ & $94,8 \pm 5,5$ & 16,99 \\
\hline Фенбендазол & 5,0 & 7 & 4 & $109,3 \pm 5,8$ & $5,3 \pm 1,0$ & 95,36 \\
\hline Контроль & - & 7 & 0 & $108,8 \pm 5,7$ & $114,2 \pm 6,5$ & - \\
\hline \multicolumn{7}{|l|}{ Фасииолез } \\
\hline СМКФ & 15,0 & 8 & 4 & $127,4 \pm 6,8$ & $12,3 \pm 2,4$ & 91,05 \\
\hline СМКФ & 7,5 & 8 & 2 & $129,2 \pm 6,7$ & $61,4 \pm 5,7$ & 55,32 \\
\hline СМКФ & 5,0 & 8 & 0 & $130,4 \pm 6,5$ & $90,5 \pm 6,3$ & 34,14 \\
\hline Фенбендазол & 5,0 & 8 & 0 & $128,7 \pm 7,0$ & $115,3 \pm 6,4$ & 16,09 \\
\hline Фенбендазол & 15,0 & 8 & 1 & $131,3 \pm 6,6$ & $58,4 \pm 4,2$ & 57,50 \\
\hline Контроль & - & 7 & 0 & $130,2 \pm 6,5$ & $137,4 \pm 7,2$ & - \\
\hline \multicolumn{7}{|l|}{ Дикрочелиоз } \\
\hline СМКФ & 15,0 & 9 & 4 & $138,2 \pm 7,2$ & $4,0 \pm 1,6$ & 97,21 \\
\hline СМКФ & 7,5 & 8 & 2 & $137,6 \pm 7,0$ & $43,6 \pm 4,7$ & 69,51 \\
\hline СМКФ & 5,0 & 8 & 0 & $138,0 \pm 6,7$ & $80,4 \pm 5,4$ & 43,78 \\
\hline Фенбендазол & 5,0 & 8 & 0 & $140,1 \pm 7,1$ & $112,9 \pm 6,7$ & 21,05 \\
\hline Фенбендазол & 15,0 & 8 & 2 & $139,6 \pm 7,3$ & $50,1 \pm 4,8$ & 64,97 \\
\hline Контроль & - & 8 & 0 & $138,7 \pm 7,2$ & $143,0 \pm 7,3$ & - \\
\hline
\end{tabular}




\begin{tabular}{|c|c|c|c|c|c|c|}
\hline 1 & 2 & 3 & 4 & 5 & 6 & 7 \\
\hline \multicolumn{7}{|l|}{ Мониезиоз } \\
\hline СМКФ & 3,0 & 9 & 7 & $168,7 \pm 7,4$ & $3,0 \pm 0,8$ & 98,28 \\
\hline СМКФ & 2,0 & 9 & 3 & $167,3 \pm 7,3$ & $65,3 \pm 4,6$ & 62,54 \\
\hline СМКФ & 1,0 & 9 & 0 & $169,2 \pm 7,0$ & $118,5 \pm 6,6$ & 32,02 \\
\hline Фенбендазол & 1,0 & 9 & 0 & $170,3 \pm 6,9$ & $147,9 \pm 6,7$ & 15,15 \\
\hline Фенбендазол & 7,5 & 9 & 5 & $171,6 \pm 6,8$ & $16,7 \pm 2,0$ & 90,42 \\
\hline Контроль & - & 9 & 0 & $170,2 \pm 6,7$ & $174,3 \pm 7,2$ & - \\
\hline \multicolumn{7}{|l|}{ Трихоцефалез } \\
\hline СМКФ & 3,0 & 8 & 5 & $119,6 \pm 6,3$ & $3,5 \pm 0,8$ & 97,18 \\
\hline СМКФ & 2,0 & 8 & 3 & $120,3 \pm 6,2$ & $45,8 \pm 4,1$ & \begin{tabular}{|l|}
63,07 \\
\end{tabular} \\
\hline СМКФ & 1,0 & 7 & 1 & $117,8 \pm 6,0$ & $85,6 \pm 5,7$ & 31,00 \\
\hline Фенбендазол & 1,0 & 7 & 0 & $118,2 \pm 5,7$ & $105,4 \pm 5,3$ & 15,00 \\
\hline Фенбендазол & 5,0 & 7 & 3 & $119,0 \pm 5,8$ & $14,0 \pm 1,4$ & 88,71 \\
\hline Контроль & - & 7 & 0 & $120,2 \pm 5,7$ & $124,0 \pm 5,8$ & - \\
\hline
\end{tabular}


Таким образом, эффективность СМКФ оказалась в 2,5-3,75 раза выше активности субстанции.

Диктиокаулез. Получена 100; 96,73 и 85,61\%-ная эффективность СМКФ в дозах 3,0; 2,0 и 1,0 мг/кг по ДВ соответственно (табл.). Субстанция фенбендазола в дозах 5,0 и 1,0 мг/кг проявила соответственно 96,32 и 13,82\%-ную эффективность. При сравнении активности СМКФ и субстанции фенбендазола в дозе по 1,0 мг/кг по ДВ установлено повышение в 6 раз действия СМКФ против диктиокаул.

Дозу СМКФ 3,0 мг/кг по ДВ рекомендуем как терапевтическую, так как она обеспечивает 100\%-ный эффект.

Стронгилоидоз. Результаты испытания СМКФ (табл.) при стронгилоидозе ягнят свидетельствуют о 100\%-ной эффективности комплекса фенбендазола в дозе 3,0 мг/кг по ДВ. СМКФ в дозах 2,0 и 1,0 мг/кг показал соответственно 71,9 и $33,9 \%$-ный эффект. Базовый препарат - субстанция фенбендазола проявил в дозе 5,0 и 1,0 мг/кг соответственно 95,36 и 16,99\%-ный эффект. Инвазированность животных контрольной группы в период опыта существенно не изменилась (Р > $0,05)$.

Таким образом, СМКФ в дозе 3,0 мг/кг по ДВ показал 100\%-ную эффективность при стронгилоидозе ягнят.

Трихоцефалез. Испытания препаратов при трихоцефалезе овец показали недостаточную эффективность СМКФ в дозах 1,0 и 2,0 мг/кг по ДВ (табл.). При повышении дозы СМКФ до 3,0 мг/кг эффективность составила 97,18 \%. Базовый препарат - субстанция фенбендазола в дозах 5,0 и 1,0 мг/кг проявил соответственно 90,33 и 15,0\%-ный эффект. При сравнении активности СМКФ и субстанции фенбендазола в дозе по 1,0 мг/кг по ДВ действие СМКФ было в 2 раза выше.

Следовательно, дозу СМКФ 3,0 мг/кг по ДВ рекомендуем как терапевтическую.

Мониезиоз. При испытании СМКФ в дозах 3,0; 2,0 и 1,0 мг/кг по ДВ ни одно животное полностью не освободилось от мониезий. Максимальной оказалась эффективность СМКФ в дозе 3,0 мг/кг. Препарат в этой дозе показал 97,18\%-ный эффект. Эффективность субстанции фенбендазола в дозах 5,0 и 1,0 мг/кг составила соответственно 88,71 и 15,0 \%. Отмечено значительное повышение эффективности СМКФ по сравнению с субстанцией фенбендазола.

Дикроцелиоз. Имеются данные об эффективности фенбендазола в повышенной дозе $(22$ мг/кг) против дикроцелий. В связи с этим нами испытан СМКФ в сравнении с субстанцией фенбендазола. СМКФ в дозах 5,0 и 7,5 мг/кг по ДВ оказался недостаточно эффективным при дикроцелиозе. При повышении дозы СМКФ до 15,0 мг/кг эффективность составила 97,21 \%. Эта доза может быть рекомендована при дикроцелиозе как терапевтическая. Субстанция фенбендазола в дозах 5,0 и 15,0 мг/кг оказалась недостаточно эффективной $(23,85$ и 64,97 \%). При сравнении эффективности СМКФ и субстанции фенбендазола в дозе по 5,0 мг/кг по ДВ активность СМКФ была в 2 раза выше. Учитывая то, что против дикроцелиев нет эффективных препаратов, полагаем, что СМКФ в дозе 15,0 мг/кг по ДВ будет альтернативой для лечения дикроцелиоза овец.

Фасциолез. Известно, что фенбендазол не является фасциолоцидным препаратом. Однако, нами проведена оценка активности СМКФ в повышенной дозе против фасциол. Мы полагали, что увеличение растворимости препарата и его биодоступности позволят повысить и его активность. СМКФ в дозах 15,0; 7,5 и 5,0 мг/кг по ДВ показал соответственно 91,0; 55,3 и 34,1\%-ный эффект. 
Субстанция фенбендазола в дозах 5,0 и 15,0 мг/кг проявила недостаточный эффект, равный соответственно 16,09 и 57,5\%.

Таким образом, инновационная технология создания супрамолекулярных комплексов на основе механохимической технологии позволяет значительно повысить эффективность фенбендазола, снизить терапевтическую дозу и расширить спектр антигельминтного действия.

\section{Заключение}

В опытах на молодняке овец, спонтанно инвазированных гельминтами, изучен спектр антигельминтного действия и установлена терапевтическая доза СМКФ, полученного по механохимической технологии с использованием в качестве адресной доставки арабиногалактана. СМКФ максимальную эффективность при основных гельминтозах овец показал в дозе 3,0 мг/кг по ДВ, а при дикроцелиозе и фасциолезе - в дозе 15,0 мг/кг по ДВ. Эффективность СМКФ оказалась в 2-3 раза выше активности субстанции фенбендазола.

\section{Литература}

1. Архипов И. А. Антигельминтики: Фармакология и применение. - М., 2009. - 409 c.

2. Варламова А. И., Лимова Ю. В., Садов К. М., Садова А. К., Белова Е. Е., Радионов А. В., Халиков С. С., Чистяченко Ю. С., Душкин А. В., Скира В. Н., Архипов И. А. Эффективность супрамолекулярного комплекса фенбендазола при нематодозах овец // Российский паразитологический журнал. - М., 2016. - Т. 35, Вып. 1. - С. 76-81.

3. Варламова А. И. Антигельминтная эффективность супрамолекулярного комплекса фенбендазола при нематодозах молодняка крупного рогатого скота // Ветеринария. - 2017. - № 1. - С. 32-35.

4. Варламова А. И., Архипов И. А., Халиков С. С., Душкин А. В., Чистяченко Ю. С., Халиков М. С., Данилевская Н. В. Антигельминтное средство и способ его получения. Патент на изобретение № 2558922 // Бюл. ФИПС. - № 22 от 10.08.2015.

5. Душкин А. В., Сунцов Л. П., Халиков С. С. Механохимическая технология для повышения растворимости лекарственных веществ // Фундаментальные исследования. - 2013. - № 1 (часть 2). - С. 448-457.

6. Bossche H., Rochette F., Horig C. Anthelmintic efficacy of fenbendazole. Vet. Rec., 1982, vol. 78, no. 3, pp. 876-877.

7. Duwel D., Strassor H. Effectiveness von fenbendazole bei parasitische Krankheiten. Dtschr. Tiearztl. Wsch., 1978, vol. 85, no. 2, pp. 239-241.

8. Kalpana P., Manish S., Dinesh S.K., Surenda J.K. Solid dispersion: apporoaches, technology involved, unmet need \& challenges. Drug Invent. Today, 2010, vol. 2, no. 7, pp. 349-357.

9. Krishnaian Y. S. R. Pharmaceutical technologies for enhancing oral bioavailability of poorly soluble drugs. J. Bioequival. Bioavailab., 2010, vol. 2, no. 2 , pp. 28-36.

10. Shinde A. J. Solubilization of poorly soluble drugs. A Review, 2007, vol. 5, no. 6, pp. $157-159$.

11. The Biopharmaceutics classification system (BCS) guidance, available at: http://www.fda.gov/AboutFDA/CentersOffices/CDER/ucml 28219.htm 


\section{References}

1. Arkhipov I. A. Antigel'mintiki: Farmakologiya i primenenie. - M., 2009. $409 \mathrm{~s}$.

2. Varlamova A. I., Limova YU. V., Sadov K. M., Sadova A. K., Belova E. E., Radionov A. V., Halikov S. S., Chistyachenko Yu. S., Dushkin A. V., Skira V. N., Arhipov I. A. Effektivnost' supramolekulyarnogo kompleksa fenbendazola pri nematodozah ovec. Rossijskij parazitologicheskij zhurnal, M., 2016, T. 35, Vyp. 1, S. 76-81.

3. Varlamova A. I. Antigel'mintnaya ehffektivnost' supramolekulyarnogo kompleksa fenbendazola pri nematodozah molodnyaka krupnogo rogatogo skota. Veterinariya, 2017, № 1, S. 32-35.

4. Varlamova A. I., Arhipov I. A., Halikov S. S., Dushkin A. V., Chistyachenko Yu. S., Halikov M. S., Danilevskaya N. V. Antigel'mintnoe sredstvo i sposob ego polucheniya. Patent na izobretenie № 2558922. Byul. FIPS, № 22 ot 10.08.2015.

5. Dushkin A. V., Suncov L. P., Halikov S. S. Mekhanohimicheskaya tekhnologiya dlya povysheniya rastvorimosti lekarstvennyh veshchestv. Fundamental'nye issledovaniya, 2013, № 1 (chast' 2), S. 448-457.

6. Bossche H., Rochette F., Horig C. Anthelmintic efficacy of fenbendazole. Vet. Rec., 1982, vol. 78, no. 3, pp. 876-877.

7. Duwel D., Strassor H. Effectiveness von fenbendazole bei parasitische Krankheiten. Dtschr. Tiearztl. Wsch., 1978, vol. 85, no. 2, pp. 239-241.

8. Kalpana P., Manish S., Dinesh S.K., Surenda J.K. Solid dispersion: apporoaches, technology involved, unmet need \& challenges. Drug Invent. Today, 2010, vol. 2, no. 7, pp. 349-357.

9. Krishnaian Y. S. R. Pharmaceutical technologies for enhancing oral bioavailability of poorly soluble drugs. J. Bioequival. Bioavailab., 2010, vol. 2, no. 2, pp. 28-36.

10. Shinde A. J. Solubilization of poorly soluble drugs. A Review, 2007, vol. 5, no. 6, pp. $157-159$.

11. The Biopharmaceutics classification system (BCS) guidance, available at: http://www.fda.gov/AboutFDA/CentersOffices/CDER/ucml 28219.htm

\section{Russian Journal of Parasitology, 2017, V.38, Iss.4}

Received 01.12.2016

Accepted 10.03.2017

\section{SPECTRUM OF ANTHELMINTIC ACTIVITY OF SUPRAMOLECULAR COMPLEX OF FENBENDAZOLE WITH ARABINOGALACTAN}

\section{Varlamova A. I., Arkhipov I. A.}

All-Russian Scientific Research Institute of Fundamental and Applied Parasitology of Animals and Plants named after K. I. Skryabin, 117218, Russia, Moscow, B. Cheremushkinskaya St., 28, e-mail: arkhipov@vniigis.ru

\section{Abstract}

Objective of research - to study the biological activity of supramolecular complex of fenbendazole with arabinogalactan against helminthoses of sheep considering spectrum of action. 
Materials and methods. Anthelmintic activity of supramolecular complex of fenbendazole with arabinogalactan (SMCF) was studied in sheep farms of the Moscow and Samara regions, which were infected with helminthoses. The experiments were made in 2014-2015 in the period of the maximal infection of animals. 386 younger sheep were used in experiments, including 50 sheep spontaneously infected with Dictyocaulus filaria, 48 - Nematodirus spp., 52 - other gastrointestinal strongylata, 47 - Fasciola hepatica, 49 - Dicrocoelium lanceatum, 42 - Strongyloides sp., 44 Trichocephalus spp., 54 - Moniezia spp. All the animals in each case of helminthoses were divided into 6 equal groups of 7-10 sheep each by the principle of analogs. SMCF was administered orally in the form of $10 \%$ powder at the dose of 1,$0 ; 2,0$ and 3,0 $\mathrm{mg} / \mathrm{kg}$ of active substance once to the sheep of the first, second and third groups. Animals of the fourth and fifth groups received the basic drug - fenbendazole at the doses respectively 1,0 and $7,5 \mathrm{mg} / \mathrm{kg}$ of bw except for the cases of fasciolosis and dicroceliasis when SMCF was administered at the doses of 15,0; 7,5 and 5,0 mg/kg and fenbendazole - at the dose of 5,0 and $15,0 \mathrm{mg} / \mathrm{kg}$. The control group did not receive the drug. The efficacy of SMCF was evaluated by the results of larvaovoscopic researches of feces by Berman's method in case of dictyocaulosis, a flotation method in case of other helminthoses before and in 15-18 days after treatment. The efficacy of SMCF was evaluated in «control test» with calculation of middle amount of eggs/larva of helminths in $1 \mathrm{~g}$ of feces.

Results and discussion. The spectrum of anthelmintic action and the therapeutic dose of SMCF with arabinogalactan, received by mechanochemical technology were studied and defined in experiments on 386 sheep, spontaneously infected with different species of helminths. SMCF showed maximum efficiency (96$100 \%$ ) in a dose of $3,0 \mathrm{mg} / \mathrm{kg}$ of active substance against main helminthoses and in a dose of $15,0 \mathrm{mg} / \mathrm{kg}$ - against dicroceliasis and fasciolosis. The efficacy of SMCF was in 2-3 times higher than activity of fenbendazole substance.

Keywords: sheep, supramolecular complex, fenbendazole, arabinogalactan, efficacy, helminthoses.

(C) 2017 The Author(s). Published by All-Russian Scientific Research Institute of Fundamental and Applied Parasitology of Animals and Plants named after K.I. Skryabin. This is an open access article under the Agreement of 02.07.2014 (Russian Science Citation Index (RSCI)http://elibrary.ru/projects/citation/cit_index.asp) and the Agreement of 12.06.2014 (CA-BI.org/Human Sciences section: http://www.cabi.org/Uploads/CABI/publishing/fulltext-products/cabi-fulltext-materialfrom-journals-by-subject-area.pdf). 